\title{
Efficacy of esomeprazole in treating acid-related diseases in Japanese populations
}

This article was published in the following Dove Press journal:

Clinical and Experimental Gastroenterology

12 May 2012

Number of times this article has been viewed

\author{
Mitsushige Sugimoto' \\ Takahisa Furuta ${ }^{2}$ \\ 'First Department of Medicine, \\ ${ }^{2}$ Center for Clinical Research, \\ Hamamatsu University School \\ of Medicine, Shizuoka, Japan
}

Correspondence: Mitsushige Sugimoto First Department of Medicine, Hamamatsu University School of Medicine, I-20-I Handayama, Higashi-ku, Hamamatsu, 43I-3192, Japan Tel +8I 53435226 I

Fax +8I 534349447

Email mitsu@hama-med.ac.jp
Abstract: Esomeprazole (Nexium ${ }^{\circledR}$; AstraZeneca), the S-isomer of omeprazole, is the first proton pump inhibitor (PPI) to be developed as an optical isomer. Compared with omeprazole, esomeprazole has an improved pharmacokinetic profile with regards to CYP2C19 (S-mephenytoin 4'-hydroxylase) genotype, showing increased systemic exposure and less interindividual variability. Further, esomeprazole is a more potent acid inhibitor than other currently available PPIs and is therefore used as a first-line drug for acid-related diseases. While esomeprazole has been available in a number of countries worldwide, the compound only received authorized permission to be marketed in Japan in September 2011. The standard esomeprazole dose in Japan for the treatment of peptic ulcers and gastroesophageal reflux disease (GERD) is $20 \mathrm{mg}$. Other advised dosages are $10 \mathrm{mg}$ for nonerosive reflux disease and $20 \mathrm{mg}$ twice-daily dosing for eradication of Helicobacter pylori. In Japanese, the effective rate of esomeprazole $20 \mathrm{mg}$ during 24 weeks for GERD patients is $92.0 \%$ (88.0\%-96.0\%), while the prevention of peptic ulcer development using $20 \mathrm{mg}$ for 24 weeks in patients treated with nonsteroidal anti-inflammatory drugs is $96.0 \%(92.8 \%-99.1 \%)$. Although clinical data are limited, the usefulness of esomeprazole is expected in Japanese subjects given the reduced prevalence of CYP2C19 rapid metabolizers in Japan compared with Western countries.

Keywords: esomeprazole, PPI, CYP2C19, peptic ulcer, GERD, H. pylori

\section{Introduction}

A wide number of proton pump inhibitors (PPIs) have been developed for the treatment of acid-related diseases. PPIs are currently the first-line treatment against acid-related diseases such as gastric and duodenal ulcers, gastroesophageal reflux disease (GERD), nonerosive reflux disease (NERD) and Zollinger-Ellison syndrome, and are used in combination with antibiotics for the eradication of Helicobacter pylori. ${ }^{1-4}$ PPIs function by first being absorbed into the small intestine and reaching the gastric parietal cells via systemic circulation, where they then disturb proton pump $\left(\mathrm{H}^{+} / \mathrm{K}^{+}\right.$-ATPase $)$activity by irreversibly binding to the pumps, thereby resulting in potent acid inhibition. 5,6 In Japan, four kinds of PPIs are available: omeprazole, lansoprazole, rabeprazole, and esomeprazole, the last of which has been approved for use in Japan only since September 2011. In this review, we focus on esomeprazole, newly available in Japan, and its efficacy in treating acid-related diseases in Japanese patients.

\section{Characteristics of esomeprazole}

PPIs are substituted benzimidazoles that exist as a racemic mixture of R-and S-isomers. Esomeprazole (Nexium ${ }^{\circledR}$; AstraZeneca, Wilmington, DE) is the S-isomer of the PPI 
omeprazole and is the first single-isomer PPI to be developed for the treatment of acid-related diseases. In general, esomeprazole more effectively inhibits gastric acid secretion than omeprazole, particularly during daytime. ${ }^{7-9}$ Esomeprazole differs from both its parent compound as well as other PPIs in that it has a lower first-pass hepatic metabolism and slower plasma clearance, which results in higher plasma concentrations. $^{7-9}$ This increased systemic bioavailability offers potentially better clinical efficacy and more effective management of acid-related diseases.

In Japan, the standard dose of esomeprazole for treatment is $20 \mathrm{mg}$ once-daily dosing (od), which is half the $40 \mathrm{mg}$ od dose more commonly used in several Western countries. Overall, the Japanese national health insurance system permits esomeprazole use for the treatment of gastric ulcers for 8 weeks (20 mg od), duodenal ulcers for 6 weeks (20 mg od), erosive GERD for 8 weeks (10-20 mg od), NERD for 8 weeks (10 mg od), for the treatment of Zollinger-Ellison syndrome (20 $\mathrm{mg}$ od), for the prevention of nonsteroidal anti-inflammatory drug (NSAID)-induced peptic ulcers (20 mg od), and for the eradication of $H$. pylori (20 mg twice-daily [bid]) for 7 days. However, because it has only recently been available in Japan, information on the pharmacological and clinical effects of esomeprazole in Japanese populations is limited.

\section{Pharmacokinetics of esomeprazole}

In human liver microsomal experiments, the metabolic rate significantly differed among three types of S-omeprazole (esomeprazole), R-omeprazole, and a racemic mixture of the two (omeprazole), with the metabolic rate for esomeprazole in relation to drug metabolic enzyme being substantially lower than that for R-omeprazole or omeprazole. ${ }^{8}$ The sum of the intrinsic clearance of all three metabolites (sulfone, hydroxyl, and 5-O-desmethyl metabolites) was 14.6 and $42.5 \mathrm{~mL} / \mathrm{min} / \mathrm{mg}$ protein for esomeprazole and R-omeprazole, respectively (Figure 1). ${ }^{7}$ The maximum plasma esomeprazole concentrations $\left(\mathrm{C}_{\max }\right)$ attained with esomeprazole were higher than those observed for the other two drugs (Table 1). ${ }^{8}$ For reference, single $20 \mathrm{mg}$ oral doses of esomeprazole generally give a $\mathrm{C}_{\max }$ value of $0.5-1.8 \mathrm{mg} / \mathrm{L}$ within $1-3$ hours of administration in Western populations. ${ }^{8-10}$ Respective area-under-the-curve (AUC) values of esomeprazole, R-omeprazole, and omeprazole were $1.52,0.62$, and $1.04 \mu \mathrm{mol} \cdot$ hour/L on Day 1 and $2.84,0.68$, and $1.63 \mu \mathrm{mol} \cdot$ hour/L on Day 5. Additionally, the AUCs of esomeprazole at 20 and $40 \mathrm{mg}$ were over 1.8 and 5.0 times higher than values for omeprazole $20 \mathrm{mg},{ }^{9}$ suggesting that after repeated administration, the $\mathrm{C}_{\max }$ values of esomeprazole and omeprazole increase by approximately $50 \%-80 \%$ and $40 \%-50 \%$, respectively, compared with that on Day $1,8,10$ and that the AUC levels of esomeprazole and omeprazole increase by approximately $80 \%$ and $50 \%$, respectively, while that of R-omeprazole is almost unchanged (Table 1). ${ }^{8}$ This change in drug exposure after repeated administration of esomeprazole and omeprazole may be due to an inhibition of cytochrome P450 (CYP) $2 \mathrm{C} 19$, one of the main drug metabolic enzymes for esomeprazole and omeprazole.

In another Phase I study of esomeprazole conducted by AstraZeneca in a Japanese population, the AUC and $\mathrm{C}_{\max }$ values on Day 5 were approximately $80 \%-100 \%$ higher than on Day 1, findings consistent with those in Western populations (Table 1). ${ }^{11}$ However, respective AUC values on Days 1 and 5 were 3.23 and $5.99 \mu \mathrm{mol} \cdot$ hour/L, respectively, values higher than those in Western populations (Table 1). This discrepancy may be due to differing frequencies of different S-mephenytoin 4'-hydroxylase (CYP2C19) genotype status

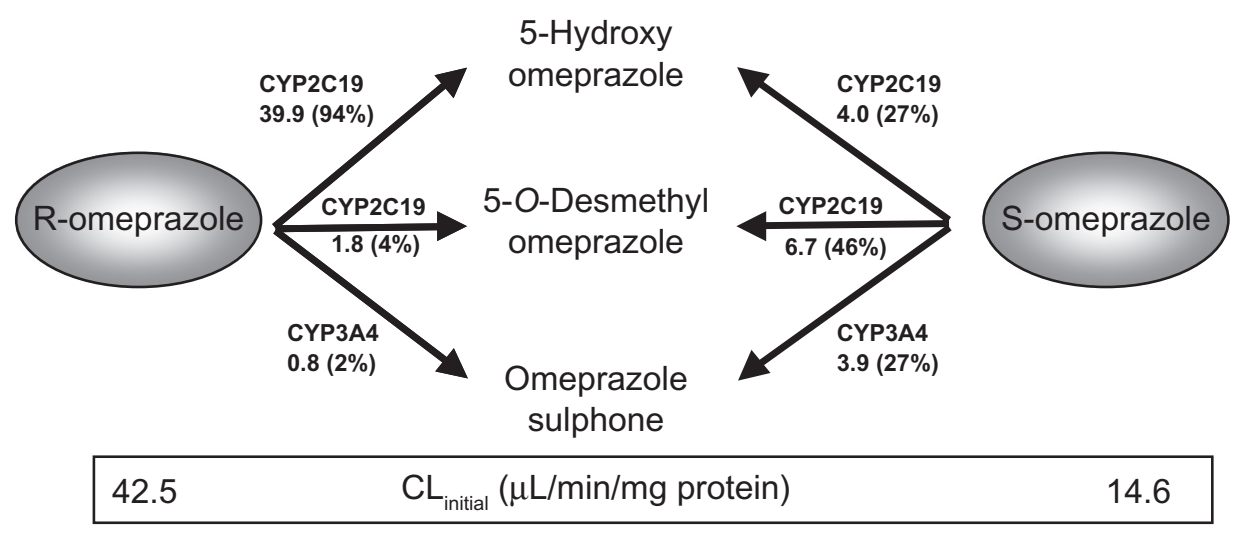

Figure I Clearance of R-omeprazole and S-omeprazole in relation to CYP2CI9 and CYP3A4. ${ }^{7}$ Clearance was I4.6 and $42.5 \mu \mathrm{L} / \mathrm{min} / \mathrm{mg}$ protein for esomeprazole and R-omeprazole. 
Table I Pharmacokinetic values for esomeprazole $20 \mathrm{mg}$

\begin{tabular}{|c|c|c|c|c|c|}
\hline & Dosage regimens & Day & S-omeprazole & Racemic & R-omeprazole \\
\hline \multirow[t]{6}{*}{ Hassan-Alin et al ${ }^{8}$ (Sweden) } & \multirow[t]{2}{*}{ AUC (ng $\cdot$ hour $/ m L)$} & I & $1.5(0.9-2.5)$ & $1.0(0.6-1.7)$ & $0.6(0.4-1.0)$ \\
\hline & & 5 & $2.8(1.7-4.8)$ & $1.6(1.0-2.8)$ & $0.7(0.4-1.2)$ \\
\hline & \multirow[t]{2}{*}{$C_{\max }(\mu \mathrm{mol} / \mathrm{L})$} & I & $1.3(0.9-1.8)$ & $1.0(0.8-1.4)$ & $0.7(0.5-1.0)$ \\
\hline & & 5 & $1.8(1.3-2.6)$ & $1.4(1.0-2.0)$ & $0.7(0.5-1.0)$ \\
\hline & \multirow[t]{2}{*}{$t_{1 / 2}$ (hour) } & 1 & $0.8(0.6-0.9)$ & $0.7(0.5-0.8)$ & $0.5(0.4-0.6)$ \\
\hline & & 5 & $1.0(0.8-1.2)$ & $0.8(0.6-1.0)$ & $0.5(0.4-0.7)$ \\
\hline \multirow[t]{6}{*}{ Andersson et al ${ }^{10}$ (Sweden) } & \multirow[t]{2}{*}{ AUC (ng $\cdot$ hour/mL) } & 1 & $1.4(1.0-2.3)$ & & \\
\hline & & 5 & $3.1(2.1-4.6)$ & & \\
\hline & \multirow[t]{2}{*}{$\mathrm{C}_{\max }(\mu \mathrm{mol} / \mathrm{L})$} & 1 & $1.7(1.3-2.2)$ & & \\
\hline & & 5 & $2.6(2.0-3.2)$ & & \\
\hline & \multirow[t]{2}{*}{$\mathrm{t}_{1 / 2}(\mathrm{~h})$} & 1 & $0.7(0.6-1.0)$ & & \\
\hline & & 5 & I.I (0.9-I.4) & & \\
\hline \multirow[t]{6}{*}{ AstraZeneca" (Japan) } & \multirow[t]{2}{*}{ AUC (ng $\cdot$ hour $/ m L)$} & 1 & $3.2(2.3-4.5)$ & & \\
\hline & & 5 & $6.0(4.3-8.4)$ & & \\
\hline & \multirow[t]{2}{*}{$C_{\max }(\mu \mathrm{mol} / \mathrm{L})$} & 1 & $1.4(1.1-1.9)$ & & \\
\hline & & 5 & $2.6(1.9-3.4)$ & & \\
\hline & \multirow{2}{*}{$\mathrm{t}_{\mathrm{t} / 2}(\mathrm{~h})$} & I & I.I (0.9-I.3) & & \\
\hline & & 5 & I.3 (I.I-I.5) & & \\
\hline
\end{tabular}

Notes: Maximum plasma concentration $\left(\mathrm{C}_{\max } ; \mathrm{ng} / \mathrm{mL}\right)$, plasma half-life time $\left(\mathrm{t}_{1 / 2} ;\right.$ hour $)$, and area under the plasma concentration-time curve $(\mathrm{AUC} ; \mathrm{ng} \cdot \mathrm{hour} / \mathrm{mL})$ are given as median values (range).

among geographic populations ${ }^{12-14}$ and to the prevalence of poor metabolizers (PMs) in that Phase I study.

\section{Pharmacodynamics}

\section{as acid-inhibiting drugs}

While acid inhibition attained with esomeprazole, R-omeprazole, and omeprazole pharmacodynamics closely correlates to their respective AUC values, an observation true for other PPIs as well, ${ }^{15,16}$ esomeprazole tends to show higher AUC values and more pronounced acid suppression than its related compounds. ${ }^{9}$ In Western populations, esomeprazole at $40 \mathrm{mg}$ maintains a percent of time of intragastric $\mathrm{pH}>4$ for approximately 6 hours longer than omeprazole at $20 \mathrm{mg}$ (16.8 vs 10.5 hours) and 4 hours longer than esomeprazole at $20 \mathrm{mg}$ (16.8 vs 12.7 hours). ${ }^{9} \mathrm{In}$ general, esomeprazole is more effective at inhibiting potent acid secretion at $40 \mathrm{mg}$ than at $20 \mathrm{mg}$, which is why many Western countries have established $40 \mathrm{mg}$ as the standard dose for the treatment of acid-related diseases. However, in Japanese, the respective percent of time of intragastric $\mathrm{pH}>4$ with esomeprazole at 40 and $20 \mathrm{mg}$ and omeprazole at $20 \mathrm{mg}$ are $62.39 \% \pm 14.40 \%(\mathrm{n}=40), 68.49 \% \pm 8.09 \%$ $(\mathrm{n}=37)$, and $58.91 \% \pm 14.40 \%(\mathrm{n}=38),{ }^{11}$ respectively, suggesting little difference in acid inhibition at esomeprazole 40 or $20 \mathrm{mg}$ in Japanese. Therefore, because acid inhibition attained with esomeprazole in Japanese may be more potent than Western populations, esomeprazole $20 \mathrm{mg}$ was selected as the standard dose.
In a randomized crossover study using $108 \mathrm{H}$. pylori-negative subjects, the percent of time of intragastric $\mathrm{pH}>4$ on Day 5 was significantly increased following esomeprazole $20 \mathrm{mg}$ compared with lansoprazole $15 \mathrm{mg}(50.4 \% \mathrm{vs}$ $43.0 \% ; P=0.03)$ and rabeprazole $10 \mathrm{mg}(59.8 \%$ vs $51.7 \%$; $P=0.01) .{ }^{17}$ However, rabeprazole at $20 \mathrm{mg}$ increased intragastric $\mathrm{pH}$ compared with esomeprazole at $20 \mathrm{mg}$ on Day 1 and showed a higher AUC and intragastric $\mathrm{pH}$ on Day $1^{18}$ while also producing greater acid suppression on Day 1 than esomeprazole at $40 \mathrm{mg}$, particularly at night. ${ }^{19}$ Findings from these studies suggest that rabeprazole has a faster onset of acid inhibitory action than esomeprazole at either 20 or $40 \mathrm{mg}$ from Day $1,{ }^{19}$ although esomeprazole remains the most effective PPI from Day 5. ${ }^{20}$ Physicians should therefore consider the time and onset of treatment when selecting a PPI.

\section{PPI-metabolizing enzyme CYP2Cl9 and its genotypes}

PPIs undergo extensive hepatic metabolism by the CYP system (Figure 2). ${ }^{21}$ Given that the principal enzyme related to the metabolism of PPIs is CYP2C19, it follows then that polymorphisms in CYP2C19 influence PPI pharmacokinetics and pharmacodynamics. Although more than 20 variant alleles of CYP2C19 have been identified, in Japanese the majority of individuals can be classified into the three genotypes, rapid extensive metabolizers (RMs), intermediate extensive metabolizers (IMs), and PMs, by identifying the CYP2C19 wild-type (CYP2C19*1) gene and the two mutated alleles, 

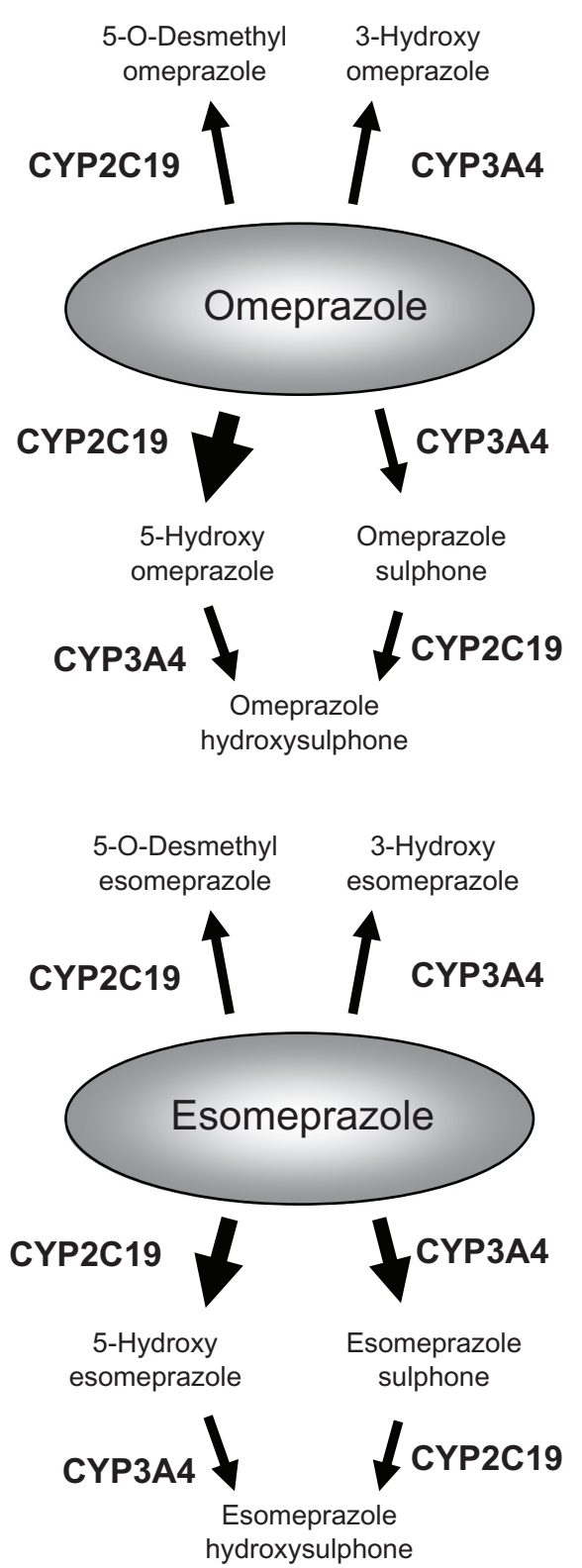

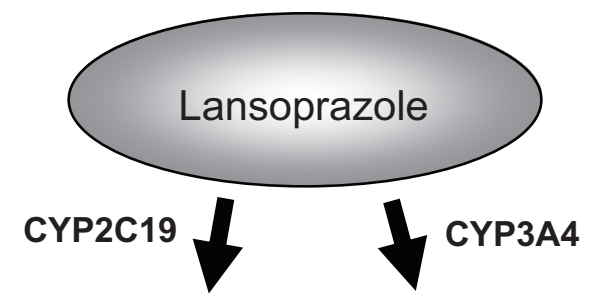

5-Hydroxy- Lansoprazolelansoprazole sulphone

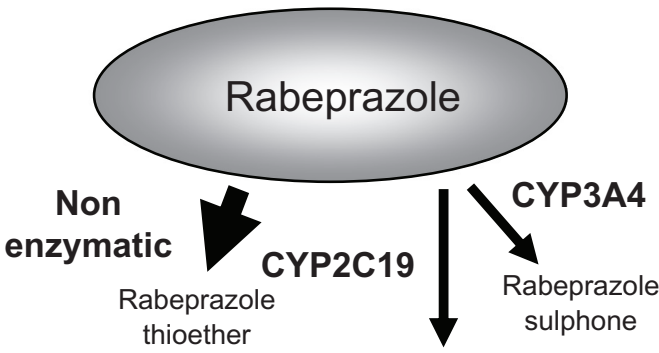

Dimethylated-rabeprazole

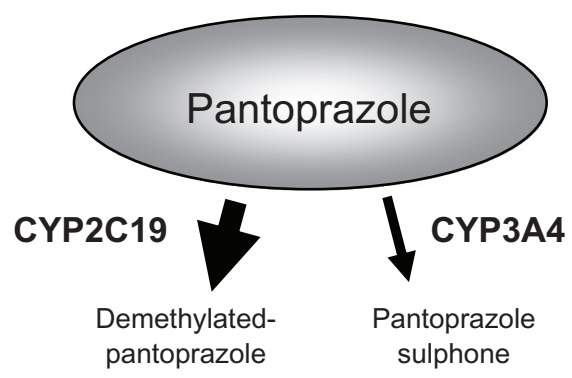

$\downarrow$ Sulfotransferase

Pantoprazole sulfate

Figure 2 Metabolic pathways of esomeprazole, omeprazole, lansoprazole, rabeprazole, and pantoprazole in relation to cytochrome P450 isoenzymes, CYP2C19 and CYP3A4.

Note: Weight of arrows indicates the relative contribution of different enzyme pathways.

CYP2C19*2 $(* 2)$ in exon 5 and CYP2C19*3 $(* 3)$ in exon 4. ${ }^{13,21-23}$ Although an ultrarapid metabolizer (CYP2C19*17) has also been reported, ${ }^{24}$ its allele carrier incidence in Japan is much lower $(2 \%)$ than in Western populations. ${ }^{25}$

Interethnic differences in the frequency of PMs are quite variable, with frequency among Asians being $5-10$ times that in other populations $(2.5 \%-3.5 \%$ in Caucasians, $13.4 \%-19.8 \%$ in Chinese, $12.6 \%$ in Koreans, and $18.0 \%-22.5 \%$ in Japanese). ${ }^{12-14}$ Additionally, the $\mathrm{C}_{\max }$ and AUC values of a given PPI differ among the three major CYP2C19 genotype groups, with the highest values seen in PMs and lowest in RMs. ${ }^{16,26,27}$ Further, the metabolic clearance value in PMs is significantly lower than in RMs or IMs, ${ }^{16,26-28}$ while greater acid inhibition by PPIs can be observed in PMs due to differing pharmacokinetics in the genotype groups (Figure $3 \mathrm{~A}-\mathrm{C}$ ). ${ }^{26-30}$

The in vitro formation of the 5-hydroxy and sulfone metabolites for both esomeprazole and R-omeprazole is mediated by CYP2C19 and CYP3A4. ${ }^{7}$ The proportion of the hydroxy metabolite from esomeprazole is less than that from R-omeprazole, while the proportion of the sulfone from esomeprazole is more, indicating that esomprazole is less 

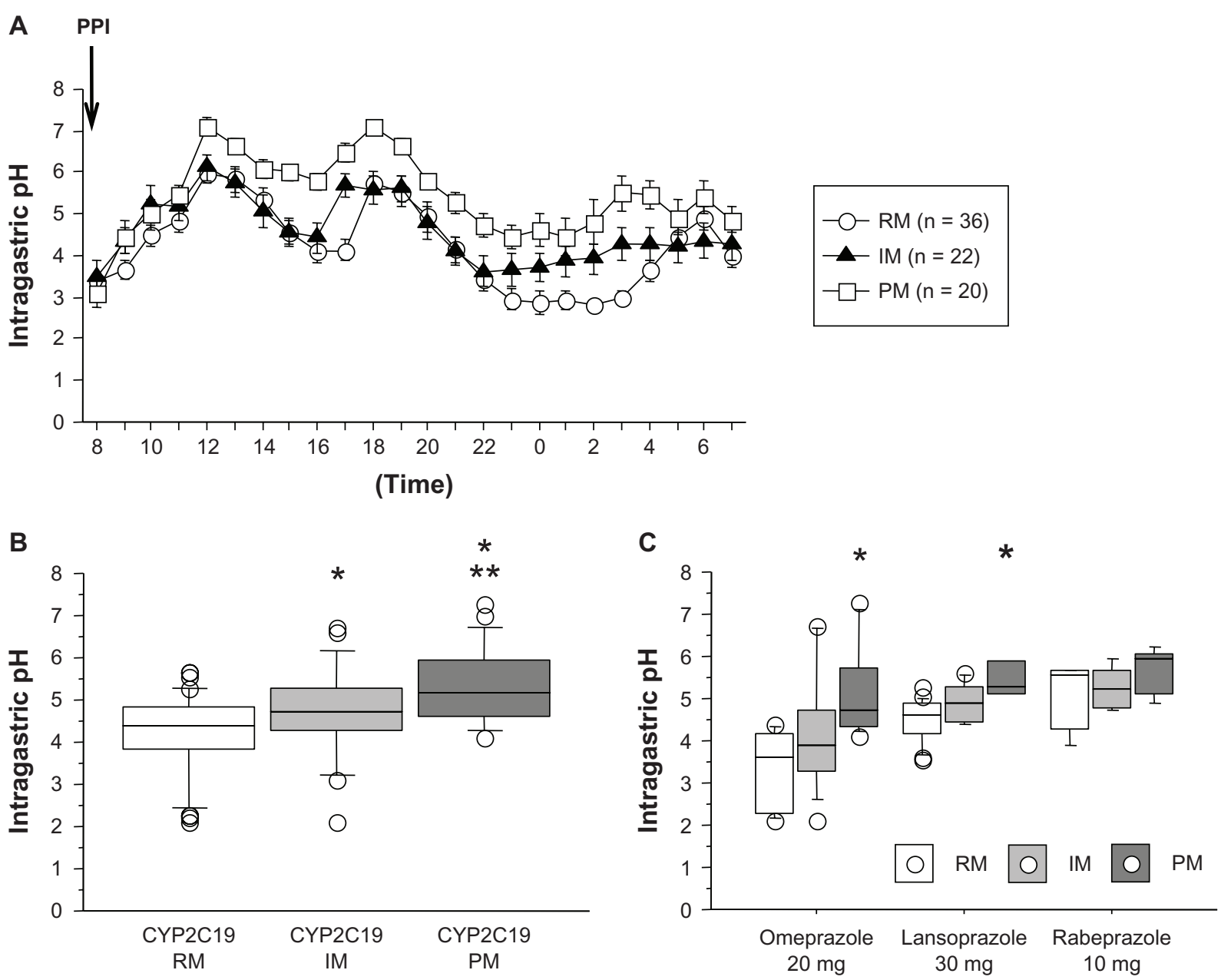

Figure 3 The 24-hour intragastric $\mathrm{pH}$ profiles after omeprazole $20 \mathrm{mg}$, lansoprazole $30 \mathrm{mg}$ or rabeprazole $10 \mathrm{mg}$, od as a function of the CYP2CI9 genotype group (A), and median 24-hour intragastric $\mathrm{pH}$ values in standard dose of PPI (B) and median 24-hour intragastric $\mathrm{pH}$ values in omeprazole, lansoprazole, or rabeprazole among different CYP2C19 genotype status (C).

Notes: *P $<0.05$ (vs. CYP2C19 RM); **P $<0.05$ (vs. CYP2CI9 IM).

Abbreviations: RM, rapid extensive metabolizer; IM, intermediate extensive metabolizer; PM, poor metabolizer; PPI, proton pump inhibitor; od, once daily dose.

dependent on CYP2C19 than CYP3A4 for its metabolism than R-omeprazole. Because the clearance is 14.6 and $42.5 \mu \mathrm{L} /$ $\mathrm{min} / \mathrm{mg}$ protein for esomeprazole and R-omeprazole, ${ }^{7}$ respectively, the effect of esomeprazole may be less than $50 \%$ that of omeprazole depending on the genotype (Figure 1). Similarly, the contribution of CYP2C19 to systemic exposure seems more pronounced when using lansoprazole (AUC ratio of PM/ extensive metabolizer, 3.7-4.6) than esomeprazole (3.1). ${ }^{31}$

A Phase I study of esomeprazole in Japan showed that the $\mathrm{AUC}$ and $\mathrm{C}_{\max }$ in CYP2C19 PMs is higher than that in RMs or IMs (Table 2). ${ }^{11}$ Because the gastric acid suppression attained by PPI is correlated to total drug exposure, these differences should be considered when treating with esomeprazole.

\section{Treatment for peptic ulcers}

The neutralization of intragastric $\mathrm{pH}$ levels using appropriate medications is important in treating peptic ulcers and prevention of rebleeding from peptic ulcers. ${ }^{32}$ Low-dose aspirin (LDA) is associated with adverse gastrointestinal effects, particularly in patients with increased gastrointestinal risk, which includes the elderly, those with a history of peptic ulcers, and those receiving concomitant treatment with other anti-platelet or anti-coagulant drugs. ${ }^{33,34}$ In blinded treatment with esomeprazole at $20 \mathrm{mg}$ or placebo for 26 weeks, the former was found to significantly reduce the cumulative proportion of patients developing LDA-induced peptic ulcers (1.1\% of patients receiving esomeprazole and $7.4 \%$ receiving placebo). ${ }^{35}$ Similarly, Yeomans et al reported that $5.4 \%$ of patients receiving placebo $(n=27 / 498)$ developed LDA-induced peptic ulcers within 26 weeks compared with $1.6 \%$ of those receiving esomeprazole $20 \mathrm{mg}$ (1.6\%, $\mathrm{n}=8 / 493){ }^{36}$ Further, Goldstein et $\mathrm{al}^{37}$ reported that esomeprazole $20 \mathrm{mg}$ was more effective in healing gastric ulcers and better tolerated in 406 patients who needed to continue 
Table 2 Pharmacokinetic values for esomeprazole $20 \mathrm{mg}$ in relation to CYP2CI9 in Japanese"

\begin{tabular}{|c|c|c|c|}
\hline Dosage regimens & RM & IM & PM \\
\hline \multicolumn{4}{|l|}{ AUC ( $\mu \mathrm{mol} \cdot$ hour/L) } \\
\hline Study I & $3.3(2.2-5.0)$ & $7.3(4.7-11.4)$ & $9.2(7.2-11.8)$ \\
\hline Study 2 & $3.4(2.5-4.6)$ & $6.0(4.7-7.7)$ & I.3 (I.I-I.5) \\
\hline \multicolumn{4}{|l|}{$C_{\max }(\mu \mathrm{mol} / \mathrm{L})$} \\
\hline Study I & $1.7(1.1-2.8)$ & $3.0(1.9-4.7)$ & $3.3(2.8-3.8)$ \\
\hline Study 2 & $1.9(1.5-2.4)$ & $2.4(2.0-3.0)$ & $2.5(1.6-3.8)$ \\
\hline \multicolumn{4}{|l|}{$\mathrm{t}_{1 / 2}$ (hour) } \\
\hline Study I & $0.9(0.7-1.1)$ & $1.3(1.0-1.7)$ & $1.6(1.3-1.9)$ \\
\hline Study 2 & $0.9(0.8-1.1)$ & $1.3(1.1-1.5)$ & $1.4(1.1-1.7)$ \\
\hline
\end{tabular}

Notes: Maximum plasma concentration $\left(\mathrm{C}_{\max } ; \mathrm{ng} / \mathrm{mL}\right)$, plasma half-life time $\left(\mathrm{t}_{1 / 2} ;\right.$ hour $)$, and area under the plasma concentration-time curve (AUC; $\mathrm{ng} \cdot \mathrm{hour} / \mathrm{mL}$ ) are given as median values (range).

Abbreviations: RM, rapid metabolizer of CYP2C19; IM, intermediate metabolizer; PM, poor metabolizer.

NSAID therapy $(122 / 138,88.4 \%, 95 \%$ confidence interval [CI]: 83.1\%-93.7\%) than ranitidine $150 \mathrm{mg}$ bid (98/132, 74.2\%; 95\% CI: 66.8\%-81.7\%). Consequently, in Western populations, an esomeprazole dose of $20 \mathrm{mg}$ appears to reduce the risk of peptic ulcers and symptoms associated with the continuous use of LDA or NSAIDs.

In Japan, esomeprazole at $20 \mathrm{mg}$ od for 4,12 , and 24 weeks in 168 patients treated with NSAIDs $(n=176)$ prevented the development of peptic ulcers in $99.4 \%$ (95\% CI: 98.2\%-100\%), 96.7\% (93.8\%-99.5\%), and 96.0\% (92.8\%-99.1\%), respectively, which are all significantly higher than placebo effects (4 weeks: $78.8 \%, 95 \% \mathrm{CI}$ : $72.6 \%-85.0 \%$; 12 weeks: $69.4 \%$, 95\% CI: $62.3 \%-76.6 \%$; and 24 weeks: $64.4 \%, 95 \% \mathrm{CI}: 58.6 \%-71.9 \% ; P<0.001) .{ }^{11}$ Further, the preventive effects for NSAIDs-induced peptic ulcers did not depend on the CYP2C19 genotype $(96.8 \%$ [90.6\%-100.0\%] in RMs, 95.7\% [91.0\%-100.0\%] in IMs, and $95.8 \%[90.2 \%-100.0 \%]$ in PMs). ${ }^{11}$ Given these findings, esomeprazole $20 \mathrm{mg}$ appears sufficient to reduce the onset of peptic ulcers in Japanese patients using LDA or NSAIDs.

\section{Treatment for GERD}

GERD, which often includes an endoscopic mucosal break in the esophagocardial (EC) junction and acid reflux-related symptoms, is a common disease that is estimated to affect around $20 \%-30 \%$ of the population worldwide. ${ }^{38}$ In Japan, although the incidence of reflux disease is increasing in Western countries, most Japanese cases of reflux disease are NERD. ${ }^{39-41}$ For effective treatment of erosive GERD using acid inhibitory drugs, intragastric $\mathrm{pH}$ over a 24-hour period should fall below $<4.0$ for no longer than $2-4$ hours (less than $<16.7 \%$ of 24 hours). ${ }^{42}$ However, we previously demonstrated that LDA-induced esophageal injury prevents or reduces acid inhibition (24-hour intragastric $\mathrm{pH}>5.0$ and $\mathrm{pH}<4.0$ less than $40 \%$ of the time) when using a PPI. ${ }^{43}$

In general, esomeprazole is more effective than omeprazole when treating erosive GERD patients. ${ }^{44,45}$ A 6-month randomized, double-blind, placebo-controlled trial investigating 375 GERD patients in the United States found respective recovery rates of $78.7 \%, 54.2 \%$, and $29.1 \%$ for patients receiving esomeprazole $20 \mathrm{mg}$, esomeprazole $10 \mathrm{mg}$, and a placebo. ${ }^{46}$ Although PPI response in patients with NERD is less effective than those with erosive GERD, ${ }^{47}$ Chinese patients with NERD showed improved reflux-related symptoms when treated with esomeprazole. ${ }^{48}$

However, other studies have shown that esomeprazole is no more effective than other PPIs when treating GERD. In a multicenter double-blind trial of esomeprazole or omeprazole at $20 \mathrm{mg}$, the cumulative healing rates at Week 8 in patients with erosive GERD were approximately equal at $90.6 \%$ and $88.3 \%$, respectively. ${ }^{49}$ In clinical trials comparing rabeprazole $10 \mathrm{mg}$ and esomeprazole $20 \mathrm{mg}$ for NERD in Asian populations, no differences were seen with regard to the primary endpoint of time to achieve a 24-hour symptomfree interval for heartburn (8.5 vs 9 days) or regurgitation (6 vs 7.5 days)..$^{50}$

The cumulative healing rates of esomeprazole $20 \mathrm{mg}$ during 4, 12, and 24 weeks for Japanese GERD patients are 97.8\% (95\% CI: 95.7\%-99.9\%), 95.0\% (91.8\%-98.2\%), and $92.0 \%(88.0 \%-96.0 \%)$, respectively. ${ }^{11}$ The effect of esomeprazole $20 \mathrm{mg}$ at 24 weeks is significantly higher than esomeprazole $10 \mathrm{mg}(82.7 \%, 95 \%$ CI: $77.2 \%-88.3 \%$; $P=0.007) .{ }^{11}$

After oral treatment for 4 weeks with esomeprazole $40 \mathrm{mg}$, the proportion of RMs, as well as IMs/PMs, is similar between the groups with complete remission and incomplete healing of GERD. ${ }^{51}$ Additionally, multivariate analysis showed that the esomeprazole effect is not dependent on the CYP2C19 genotype for complete and incomplete endoscopic healing.

\section{$H$. pylori eradication therapy in Japan}

In Japan, eradication of H. pylori is performed for patients with peptic ulcers, mucosa-associate lymphoid tissue lymphoma, idiopathic thrombocytopenic purpura, and early gastric cancer resected by endoscopy. ${ }^{52}$ The first-line regimen for eradication consists of a PPI administered bid, amoxicillin at $750 \mathrm{mg}$ bid, and clarithromycin at 200 or $400 \mathrm{mg}$ bid for 1 week, while the second-line regimen consists of a PPI bid, amoxicillin at $750 \mathrm{mg}$ bid, and metronidazole at 
$250 \mathrm{mg}$ bid for 1 week. ${ }^{53}$ Major causative factors associated with eradication failure include bacterial resistance to clarithromycin ${ }^{53}$ and insufficient gastric acid inhibition during treatment. ${ }^{4}$ Indeed, a recent increase in the prevalence of clarithromycin-resistant strains in Japan to more than $30 \%$ has been accompanied by a reduction in eradication rates with the clarithromycin-based regimen. ${ }^{53-55}$

\section{Importance of gastric acid inhibition for $H$. pylori eradication}

As mentioned above, efforts to eradicate $H$. pylori often fail due to insufficient acid inhibition. Because clarithromycin and amoxicillin are acid-sensitive, acid secretion must be potently inhibited by a PPI to prevent their degradation at low $\mathrm{pH} .{ }^{56}$ Such potent acid inhibition increases the stability and bioavailability of antibiotics in the stomach and also increases the concentration of antibiotics in gastric mucosa. ${ }^{57-59}$ For example, raising the $\mathrm{pH}$ from 3.5 to 5.5 increases the in vitro effectiveness of amoxicillin more than 10 -fold..$^{57}$ Additionally, acid inhibition allows H. pylori to reach its growth phase, rendering the bacteria more sensitive to antibiotics. ${ }^{59}$

We previously reported that the $\mathrm{pH}$ level over a 24-hour period was significantly higher in patients who achieved successful eradication using lansoprazole plus amoxicillin/ clarithromycin as a first line-treatment (6.4 [5.0-7.6]) than those who did not (5.2 [2.2-6.2]), and that when the percent-time for $\mathrm{pH}<4$ was $<10 \%$ and the 24-hour $\mathrm{pH}$ level was $>6.0$, we were able to achieve eradication in a majority of patients, irrespective of the bacterial susceptibility to clarithromycin. ${ }^{4}$ As a corollary, when using a PPI/ amoxicillin/clarithromycin regimen, the longer the period of elevated $\mathrm{pH}$ during treatment, the higher the eradication rates. In our unpublished data, intragastric $\mathrm{pH}$ and percenttime of $\mathrm{pH}<4$ on esomeprazole $20 \mathrm{mg}$ bid in $H$. pylorinegative, healthy young volunteers with high acid secretion were $5.4(5.2-6.1)$ and $25.6 \%(15.0 \%-31.2 \%)$ (Figure 4$)$. These findings strongly suggest that esomeprazole can effectively eradicate $H$. pylori in Japanese populations provided sufficient acid inhibition is achieved.
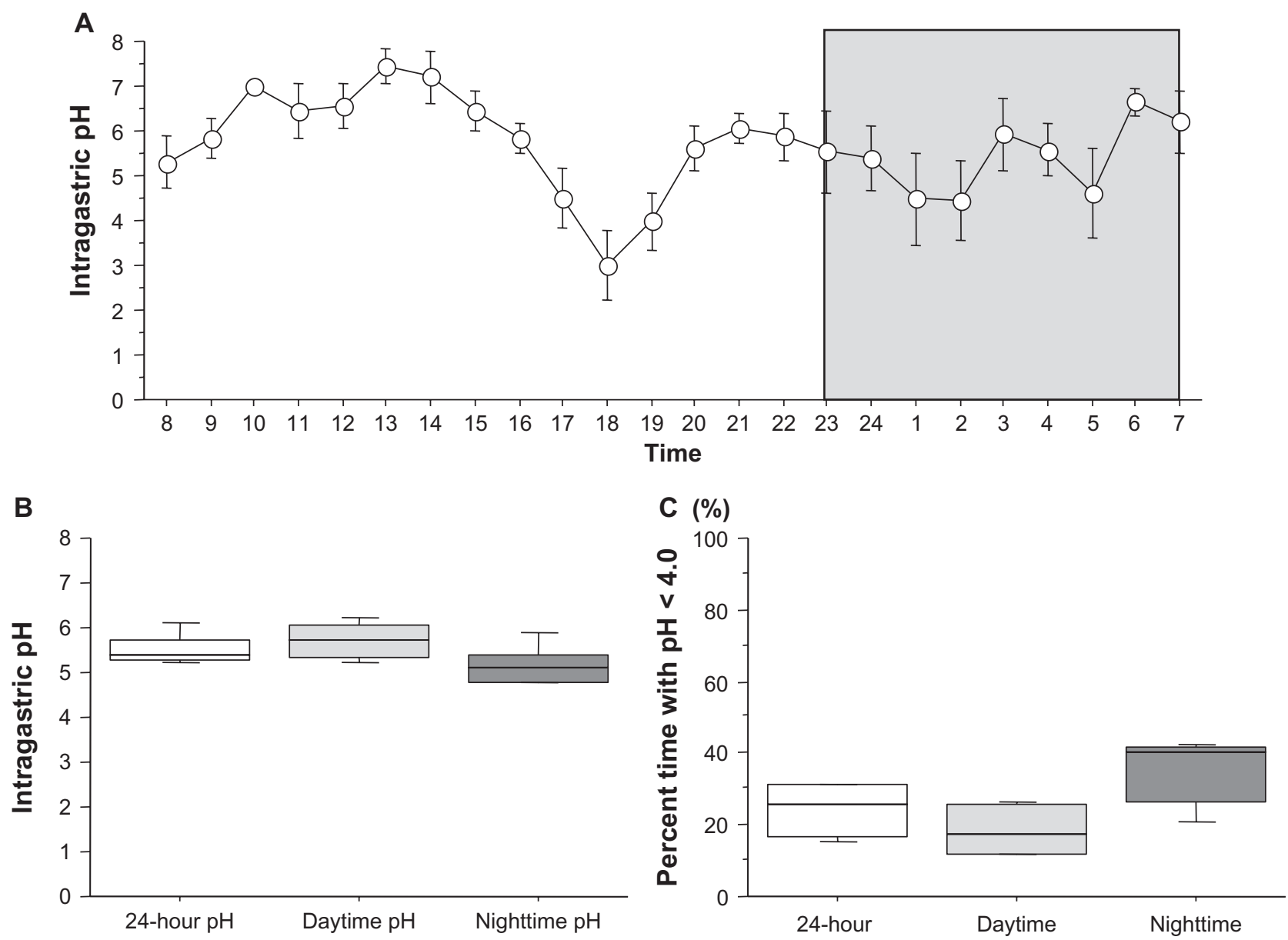

Figure 4 The 24-hour intragastric $\mathrm{pH}$ profile $(\mathbf{A})$, median intragastric $\mathrm{pH}$ value (B), and percent time with $\mathrm{pH}<4$ (C) during esomeprazole 20 mg bid treatment for 7 days. 


\section{Esomeprazole-based $\mathrm{H}$. pylori eradication therapy}

A randomized study from Taiwan shows that the eradication rate when treated with clarithromycin $500 \mathrm{mg}$, amoxicillin $1 \mathrm{~g}$, and esomeprazole $40 \mathrm{mg}$ bid for 1 week is $86 \%$ in the intention-to-treat (ITT) population. ${ }^{60}$ First-line H. pylori eradication therapy with levofloxacin/amoxicillin plus esomeprazole at $20 \mathrm{mg}$ bid in Chinese patients was $85.2 \%$ effective. ${ }^{61}$ Further, the eradication rate by ITT analysis was $74.0 \%$ with clarithromycin at $500 \mathrm{mg}$, amoxicillin $1000 \mathrm{mg}$, and esomeprazole $20 \mathrm{mg}$ bid for 7 days; $78.0 \%$ using the same antibiotics plus esomeprazole $40 \mathrm{mg}$ bid for 7 days; and $80.0 \%$ for 10 days. ${ }^{62}$ That report also suggested that neither esomeprazole dosage nor dosing duration have additive effects on $H$. pylori eradication rates. Although some reports have shown that esomeprazole at $20 \mathrm{mg}$ has an $H$. pylori eradication rate similar to that of omeprazole at $20 \mathrm{mg},{ }^{63,64}$ the rate has also been shown to significantly differ between esomeprazole-based and other PPI-based regimens, such as pantoprazole-based treatment (ITT analysis: $94 \%$ vs $82 \% ; P=0.009){ }^{65}$

\section{Influence of CYP2C19 polymorphisms on esomeprazole-based $H$. pylori eradication therapy}

In Japanese populations, the eradication rates of $H$. pylori by PPI-based eradication therapy differ by CYP2C19 genotype. ${ }^{66,67}$ Indeed, eradication rates with triple therapy of PPI bid, amoxicillin $250 \mathrm{mg}$ three times daily (tid), and clarithromycin $200 \mathrm{mg}$ tid for 1 week were $72.7 \%$ in RMs, $92.1 \%$ in IMs, and $97.8 \%$ in PMs. ${ }^{55}$ Further, a standard first-line regimen showed eradication rates of $57.7 \%$ in RMs, $71.6 \%$ in IMs, and $91.7 \%$ in PMs. ${ }^{68}$ Meta-analysis has shown the absolute risk of genetic differences in eradication failure by PPI-based regimens. ${ }^{51}$ Taken together, these reports demonstrate that one reason for the failed eradication by PPI-based therapy is insufficient acid inhibition in CYP2C19 RMs.

However, eradication rates with esomeprazole-based treatment (20 mg and $40 \mathrm{mg}$ bid) have been shown to be independent of CYP2C19 genotype (RM: 87\%, IM: 93\%, and PM: $92 \%$ in one study; ${ }^{69}$ and RM: $93 \%$, IM: $93 \%$, and PM: $95 \%$ in another). ${ }^{60}$ Pan et $a l^{61}$ reported similar findings using esomeprazole/levofloxacin/amoxicillin in Chinese populations (RM: 82\% [41/50], IM: 82\% [50/61], and PM: $89 \%$ [32/36]). In general, no previous reports have found significant differences in eradication rate for esomeprazolebased treatment among CYP2C19 genotypes.
Interestingly, although eradication rates are significantly higher in esomeprazole-based regimens than omeprazolebased ones ( $93 \%$ vs $76 \% ; P<0.05)$, this advantage is observed only in RMs.$^{60}$ Esomeprazole at $40 \mathrm{mg}$ bid for triple therapy may improve the H. pylori eradication compared to omeprazole-based therapy, but likely only in CYP2C19 RMs, as the eradication rates between omeprazole-based and esomeprazole-based regimens are similar in IMs and PMs. ${ }^{60}$

\section{Summary}

Compared to omeprazole, esomeprazole is a popular PPI with a better pharmacokinetic profile for the treatment of acidrelated diseases, has a higher AUC, and less interindividual variability. However, due to its relatively recent release in Japan, little data are available on its efficacy in Japanese patients. Nevertheless, findings in other populations suggest that esomeprazole will be effective in treating peptic ulcers, GERD, and H. pylori in Japanese populations, too.

Because CYP2C19 RM in Japanese is only 30\%, which is significantly lower than that in Western population $(70 \%)$, it is unclear whether this factor means that the clinical results from the treatment of esomeprazole in Japanese are significant. However, this factor cannot ignore acid-related disease, because the prevalence of GERD, NERD, and LDA-related peptic ulcer, which require more potent acid inhibition, is increasing in Japan and a cure rate of GERD and peptic ulcer by PPI treatment differed among Japanese with different CYP2C19 genotype status. ${ }^{3,70}$ Further study will be required to increase new knowledge of esomeprazole in Japanese.

\section{Key points}

- Esomeprazole is now used as a first-line drug for the treatment of acid-related diseases such as peptic ulcers, GERD, NERD, Zollinger-Ellison syndrome, and H. pylori infection in the world.

- Esomeprazole is the first PPI developed as a single isomer, and its metabolism is less dependent on CYP2C19 than CYP3A4 compared to R-omeprazole.

- Although the clearance of esomeprazole is approximately $50 \%$ less than omeprazole, the efficacy of esomeprazole on different CYP2C19 genotypes should not be completely ignored.

- CYP2C19 RM patients in particular should be assigned esomeprazole-based treatment against acid-related diseases.

- In Japan, the standard dose of esomeprazole for treatment is $20 \mathrm{mg}$ od, whereas the standard dose in most Western countries is $40 \mathrm{mg}$ od. 


\section{Acknowledgments}

A grant-in-aid was received from the Ministry of Education, Culture, Sports, Science and Technology of Japan (23590913).

\section{Disclosure}

The authors declare they have no conflicts of interest with regard to this work.

\section{References}

1. Walsh JH, Peterson WL. The treatment of Helicobacter pylori infection in the management of peptic ulcer disease. N Engl J Med. 1995;333(15): 984-991.

2. Furuta T, Sagehashi Y, Shirai N, et al. Influence of CYP2C19 polymorphism and Helicobacter pylori genotype determined from gastric tissue samples on response to triple therapy for $\mathrm{H}$ pylori infection. Clin Gastroenterol Hepatol. 2005;3(6):564-573.

3. Furuta T, Shirai N, Watanabe F, et al. Effect of cytochrome $\mathrm{P} 4502 \mathrm{C} 19$ genotypic differences on cure rates for gastroesophageal reflux disease by lansoprazole. Clin Pharmacol Ther. 2002;72(4):453-460.

4. Sugimoto M, Furuta T, Shirai N, et al. Evidence that the degree and duration of acid suppression are related to Helicobacter pylori eradication by triple therapy. Helicobacter. 2007;12(4):317-323.

5. Hixson LJ, Kelley CL, Jones WN, Tuohy CD. Current trends in the pharmacotherapy for peptic ulcer disease. Arch Intern Med. 1992;152(4):726-732.

6. Sachs G, Shin JM, Briving C, Wallmark B, Hersey S. The pharmacology of the gastric acid pump: the $\mathrm{H}+, \mathrm{K}+$ ATPase. Annu Rev Pharmacol Toxicol. 1995;35:277-305.

7. Abelo A, Andersson TB, Antonsson M, Naudot AK, Skanberg I, Weidolf L. Stereoselective metabolism of omeprazole by human cytochrome P450 enzymes. Drug Metab Dispos. 2000;28(8):966-972.

8. Hassan-Alin M, Andersson T, Niazi M, Rohss K. A pharmacokinetic study comparing single and repeated oral doses of $20 \mathrm{mg}$ and $40 \mathrm{mg}$ omeprazole and its two optical isomers, S-omeprazole (esomeprazole) and R-omeprazole, in healthy subjects. Eur J Clin Pharmacol. 2005;60(11):779-784.

9. Lind T, Rydberg L, Kyleback A, et al. Esomeprazole provides improved acid control vs omeprazole In patients with symptoms of gastrooesophageal reflux disease. Aliment Pharmacol Ther. 2000;14(7): 861-867.

10. Andersson T, Rohss K, Bredberg E, Hassan-Alin M. Pharmacokinetics and pharmacodynamics of esomeprazole, the S-isomer of omeprazole. Aliment Pharmacol Ther. 2001;15(10):1563-1569.

11. AstraZeneca. Interview form of Esomeprazole. Available from: http:// www.info.pmda.go.jp/go/interview/1/670227_2329029M1027_1_031 _1F. Accessed April 1, 2012: In Japanese.

12. Ishizaki T, Sohn DR, Kobayashi K, et al. Interethnic differences in omeprazole metabolism in the two S- mephenytoin hydroxylation phenotypes studied in Caucasians and Orientals. Ther Drug Monit. 1994;16(2):214-215.

13. Kubota T, Chiba K, Ishizaki T. Genotyping of S-mephenytoin 4 '-hydroxylation in an extended Japanese population. Clin Pharmacol Ther. 1996;60(6):661-666.

14. de Morais SM, Goldstein JA, Xie HG, et al. Genetic analysis of the S-mephenytoin polymorphism in a Chinese population. Clin Pharmacol Ther. 1995;58(4):404-411.

15. Lind T, Cederberg C, Ekenved G, Haglund U, Olbe L. Effect of omeprazole--a gastric proton pump inhibitor - on pentagastrin stimulated acid secretion in man. Gut. 1983;24(4):270-276.

16. Sugimoto M, Furuta T, Shirai N, et al. Different dosage regimens of rabeprazole for nocturnal gastric acid inhibition in relation to cytochrome P450 2C19 genotype status. Clin Pharmacol Ther. 2004;76(4):290-301.
17. Rohss K, Wilder-Smith C, Naucler E, Jansson L. Esomeprazole $20 \mathrm{mg}$ provides more effective intragastric Acid control than maintenance-dose rabeprazole, lansoprazole or pantoprazole in healthy volunteers. Clin Drug Invest. 2004;24(1):1-7.

18. Warrington S, Baisley K, Boyce M, Tejura B, Morocutti A, Miller N. Effects of rabeprazole, $20 \mathrm{mg}$, or esomeprazole, $20 \mathrm{mg}$, on 24-h intragastric $\mathrm{pH}$ and serum gastrin in healthy subjects. Aliment Pharmacol Ther. 2002;16(7):1301-1307.

19. Pantoflickova D, Dorta G, Ravic M, Jornod P, Blum AL. Acid inhibition on the first day of dosing: comparison of four proton pump inhibitors. Aliment Pharmacol Ther. 2003;17(12):1507-1514.

20. Wilder-Smith CH, Rohss K, Nilsson-Pieschl C, Junghard O, Nyman L. Esomeprazole $40 \mathrm{mg}$ provides improved intragastric acid control as compared with lansoprazole $30 \mathrm{mg}$ and rabeprazole $20 \mathrm{mg}$ in healthy volunteers. Digestion. 2003;68(4):184-188.

21. Ishizaki T, Horai Y. Review article: cytochrome P450 and the metabolism of proton pump inhibitors - emphasis on rabeprazole. Aliment Pharmacol Ther. 1999;13 Suppl 3:27-36.

22. Chang M, Dahl ML, Tybring G, Gotharson E, Bertilsson L. Use of omeprazole as a probe drug for CYP2C19 phenotype in Swedish Caucasians: comparison with S-mephenytoin hydroxylation phenotype and CYP2C19 genotype. Pharmacogenetics. 1995;5(6):358-363.

23. Chang M, Tybring G, Dahl ML, et al. Interphenotype differences in disposition and effect on gastrin levels of omeprazole - suitability of omeprazole as a probe for CYP2C19. Br J Clin Pharmacol. 1995;39(5):511-518.

24. Sim SC, Risinger C, Dahl ML, et al. A common novel CYP2C19 gene variant causes ultrarapid drug metabolism relevant for the drug response to proton pump inhibitors and antidepressants. Clin Pharmacol Ther. 2006;79(1):103-113.

25. Sugimoto K, Uno T, Yamazaki H, Tateishi T. Limited frequency of the CYP2C19*17 allele and its minor role in a Japanese population. Br J Clin Pharmacol. 2008;65(3):437-439.

26. Shirai N, Furuta T, Moriyama Y, et al. Effects of CYP2C19 genotypic differences in the metabolism of omeprazole and rabeprazole on intragastric pH. Aliment Pharmacol Ther. 2001;15(12):1929-1937.

27. Shirai N, Furuta T, Xiao F, et al. Comparison of lansoprazole and famotidine for gastric acid inhibition during the daytime and nighttime in different CYP2C19 genotype groups. Aliment Pharmacol Ther. 2002;16(4):837-846.

28. Sugimoto M, Furuta T, Shirai N, et al. Comparison of an increased dosage regimen of rabeprazole versus a concomitant dosage regimen of famotidine with rabeprazole for nocturnal gastric acid inhibition in relation to cytochrome P450 2C19 genotypes. Clin Pharmacol Ther. 2005;77(4):302-311.

29. Furuta T, Ohashi K, Kosuge K, et al. CYP2C19 genotype status and effect of omeprazole on intragastric $\mathrm{pH}$ in humans. Clin Pharmacol Ther. 1999;65(5):552-561.

30. Furuta T, Shirai N, Xiao F, Ohashi K, Ishizaki T. Effect of high-dose lansoprazole on intragastic $\mathrm{pH}$ in subjects who are homozygous extensive metabolizers of cytochrome P4502C19. Clin Pharmacol Ther. 2001;70(5):484-492.

31. Klotz U, Schwab M, Treiber G. CYP2C19 polymorphism and proton pump inhibitors. Basic Clin Pharmacol Toxicol. 2004;95(1):2-8.

32. Barer D, Ogilvie A, Henry D, et al. Cimetidine and tranexamic acid in the treatment of acute upper-gastrointestinal-tract bleeding. $N$ Engl $J$ Med. 1983;308(26):1571-1575.

33. Sugimoto M, Nishino M, Kodaira C, et al. Esophageal mucosal injury with low-dose aspirin and its prevention by rabeprazole. J Clin Pharmacol. 2010;50(3):320-330.

34. Nishino M, Sugimoto M, Kodaira C, et al. Preventive effects of lansoprazole and famotidine on gastric mucosal injury induced by low-dose aspirin in Helicobacter pylori-negative healthy volunteers. J Clin Pharmacol. 2011;51(7):1079-1086.

35. Scheiman JM, Devereaux PJ, Herlitz J, et al. Prevention of peptic ulcers with esomeprazole in patients at risk of ulcer development treated with low-dose acetylsalicylic acid: a randomised, controlled trial (OBERON). Heart. 2011;97(10):797-802. 
36. Yeomans N, Lanas A, Labenz J, et al. Efficacy of esomeprazole (20 mg once daily) for reducing the risk of gastroduodenal ulcers associated with continuous use of low-dose aspirin. Am J Gastroenterol. 2008;103(10):2465-2473.

37. Goldstein JL, Johanson JF, Suchower LJ, Brown KA. Healing of gastric ulcers with esomeprazole versus ranitidine in patients who continued to receive NSAID therapy: a randomized trial. Am J Gastroenterol. 2005;100(12):2650-2657.

38. Nasseri-Moghaddam S, Mofid A, Ghotbi MH, et al. Epidemiological study of gastro-oesophageal reflux disease: reflux in spouse as a risk factor. Aliment Pharmacol Ther. 2008;28(1):144-153.

39. Nagahara A, Miwa H, Minoo T, et al. Increased esophageal sensitivity to acid and saline in patients with nonerosive gastro-esophageal reflux disease. J Clin Gastroenterol. 2006;40(10):891-895.

40. Miwa H, Sasaki M, Furuta T, et al. Efficacy of rabeprazole on heartburn symptom resolution in patients with non-erosive and erosive gastrooesophageal reflux disease: a multicenter study from Japan. Aliment Pharmacol Ther. 2007;26(1):69-77.

41. Joh T, Miwa H, Higuchi K, et al. Validity of endoscopic classification of nonerosive reflux disease. J Gastroenterol. 2007;42(6):444-449.

42. Bell NJ, Burget D, Howden CW, Wilkinson J, Hunt RH. Appropriate acid suppression for the management of gastro-oesophageal reflux disease. Digestion. 1992;51 Suppl 1:59-67.

43. Sugimoto M, Nishino M, Kodaira C, et al. Impact of acid inhibition on esophageal mucosal injury induced by low-dose aspirin. Digestion. 2011;85(1):9-17.

44. Kahrilas PJ, Falk GW, Johnson DA, et al. Esomeprazole improves healing and symptom resolution as compared with omeprazole in reflux oesophagitis patients: a randomized controlled trial. The Esomeprazole Study Investigators. Aliment Pharmacol Ther. 2000;14(10):1249-1258.

45. Richter JE, Kahrilas PJ, Johanson J, et al. Efficacy and safety of esomeprazole compared with omeprazole in GERD patients with erosive esophagitis: a randomized controlled trial. Am J Gastroenterol. 2001;96(3):656-665.

46. Vakil NB, Shaker R, Johnson DA, et al. The new proton pump inhibitor esomeprazole is effective as a maintenance therapy in GERD patients with healed erosive oesophagitis: a 6-month, randomized, double-blind, placebo-controlled study of efficacy and safety. Aliment Pharmacol Ther. 2001;15(7):927-935.

47. Fass R. Epidemiology and pathophysiology of symptomatic gastroesophageal reflux disease. Am J Gastroenterol. 2003;98 (Suppl 3):S2-S7.

48. Tan VP, Wong WM, Cheung TK, et al. Treatment of non-erosive reflux disease with a proton pump inhibitor in Chinese patients: a randomized controlled trial. J Gastroenterol. 2011;46(7):906-912.

49. Lightdale CJ, Schmitt C, Hwang C, Hamelin B. A multicenter, randomized, double-blind, 8-week comparative trial of low-dose esomeprazole $(20 \mathrm{mg})$ and standard-dose omeprazole $(20 \mathrm{mg})$ in patients with erosive esophagitis. Dig Dis Sci. 2006;51(5):852-857.

50. Fock KM, Teo EK, Ang TL, Chua TS, Ng TM, Tan YL. Rabeprazole vs esomeprazole in non-erosive gastro-esophageal reflux disease: a randomized, double-blind study in urban Asia. World J Gastroenterol. 2005;11(20):3091-3098.

51. Schwab M, Schaeffeler E, Klotz U, Treiber G. CYP2C19 polymorphism is a major predictor of treatment failure in white patients by use of lansoprazole-based quadruple therapy for eradication of Helicobacter pylori. Clin Pharmacol Ther. 2004;76(3):201-209.

52. Asaka M, Kato M, Takahashi S, et al. Guidelines for the management of Helicobacter pylori infection in Japan: 2009 revised edition. Helicobacter. 2010;15(1):1-20.

53. Asaka M, Sugiyama T, Kato M, et al. A multicenter, double-blind study on triple therapy with lansoprazole, amoxicillin and clarithromycin for eradication of Helicobacter pylori in Japanese peptic ulcer patients. Helicobacter. 2001;6(3):254-261.
54. Murakami K, Sato R, Okimoto T, et al. Eradication rates of clarithromycin-resistant Helicobacter pylori using either rabeprazole or lansoprazole plus amoxicillin and clarithromycin. Aliment Pharmacol Ther. 2002;16(11):1933-1938.

55. Furuta T, Shirai N, Takashima M, et al. Effect of genotypic differences in CYP2C19 on cure rates for Helicobacter pylori infection by triple therapy with a proton pump inhibitor, amoxicillin, and clarithromycin. Clin Pharmacol Ther. 2001;69(3):158-168.

56. Peterson WL. The role of antisecretory drugs in the treatment of Helicobacter pylori infection. Aliment Pharmacol Ther. 1997;11 Suppl 1:21-25.

57. Grayson ML, Eliopoulos GM, Ferraro MJ, Moellering RC Jr. Effect of varying $\mathrm{pH}$ on the susceptibility of Campylobacter pylori to antimicrobial agents. Eur J Clin Microbiol Infect Dis. 1989;8(10): 888-889.

58. Goddard AF, Jessa MJ, Barrett DA, et al. Effect of omeprazole on the distribution of metronidazole, amoxicillin, and clarithromycin in human gastric juice. Gastroenterology. 1996;111(2):358-367.

59. Scott D, Weeks D, Melchers K, Sachs G. The life and death of Helicobacter pylori. Gut. 1998;43 Suppl 1:S56-S60.

60. Sheu BS, Kao AW, Cheng HC, et al. Esomeprazole $40 \mathrm{mg}$ twice daily in triple therapy and the efficacy of Helicobacter pylori eradication related to CYP2C19 metabolism. Aliment Pharmacol Ther. 2005;21(3):283-288.

61. Pan X, Li Y, Qiu Y, et al. Efficacy and tolerability of first-line triple therapy with levofloxacin and amoxicillin plus esomeprazole or rabeprazole for the eradication of Helicobacter pylori infection and the effect of CYP2C19 genotype: a 1-week, randomized, open-label study in Chinese adults. Clin Ther. 2010;32(12):2003-2011.

62. Gisbert JP, Dominguez-Munoz A, Dominguez-Martin A, Gisbert JL, Marcos S. Esomeprazole-based therapy in Helicobacter pylori eradication: any effect by increasing the dose of esomeprazole or prolonging the treatment? Am J Gastroenterol. 2005;100(9):1935-1940.

63. Miehlke S, Schneider-Brachert W, Bastlein E, et al. Esomeprazole-based one-week triple therapy with clarithromycin and metronidazole is effective in eradicating Helicobacter pylori in the absence of antimicrobial resistance. Aliment Pharmacol Ther. 2003;18(8):799-804.

64. Vergara M, Vallve M, Gisbert JP, Calvet X. Meta-analysis: comparative efficacy of different proton-pump inhibitors in triple therapy for Helicobacter pylori eradication. Aliment Pharmacol Ther. 2003;18(6):647-654.

65. Hsu PI, Lai KH, Lin CK, et al. A prospective randomized trial of esomeprazole- versus pantoprazole-based triple therapy for Helicobacter pylori eradication. Am J Gastroenterol. 2005;100(11):2387-2392.

66. Kurzawski M, Gawronska-Szklarz B, Wrzesniewska J, Siuda A, Starzynska T, Drozdzik M. Effect of CYP2C19*17 gene variant on Helicobacter pylori eradication in peptic ulcer patients. Eur J Clin Pharmacol. 2006;62(10):877-880.

67. Padol S, Yuan Y, Thabane M, Padol IT, Hunt RH. The effect of CYP2C19 polymorphisms on $\mathrm{H}$. pylori eradication rate in dual and triple first-line PPI therapies: a meta-analysis. Am J Gastroenterol. 2006;101(7):1467-1475.

68. Furuta T, Shirai N, Kodaira M, et al. Pharmacogenomics-based tailored versus standard therapeutic regimen for eradication of H. pylori. Clin Pharmacol Ther. 2007;81(4):521-528.

69. Lee VW, Chau TS, Chan AK, et al. Pharmacogenetics of esomeprazole or rabeprazole-based triple therapy in Helicobacter pylori eradication in Hong Kong non-ulcer dyspepsia Chinese subjects. J Clin Pharm Ther. 2010;35(3):343-350.

70. Ando T, Kato H, Sugimoto N, et al. A comparative study on endoscopic ulcer healing of omeprazole versus rabeprazole with respect to CYP2C19 genotypic differences. Dig Dis Sci. 2005;50(9): $1625-1631$. 
Clinical and Experimental Gastroenterology

Dovepress

\section{Publish your work in this journal}

Clinical and Experimental Gastroenterology is an international, peerreviewed, open access journal, publishing all aspects of gastroenterology in the clinic and laboratory, including: Pathology, pathophysiology of gastrointestinal disease; Investigation and treatment of gastointestinal disease; Pharmacology of drugs used in the alimentary tract;

Immunology/genetics/genomics related to gastrointestinal disease. This journal is indexed on CAS. The manuscript management system is completely online and includes a very quick and fair peer-review system. Visit http://www.dovepress.com/testimonials.php to read real quotes from published authors.

Submit your manuscript here: http://www.dovepress.com/clinical-and-experimental-gastroenterology-journal 